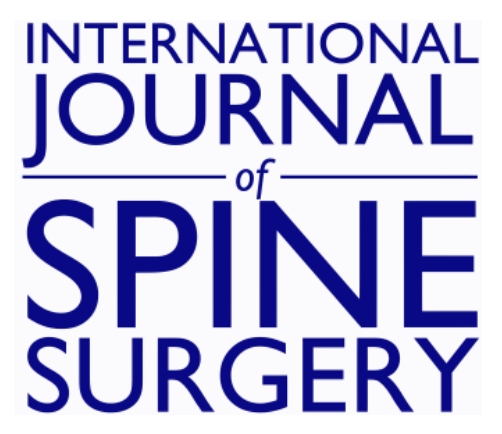

\title{
Expandable Interbody Spacers: A Two-Year Study Evaluating Radiologic and Clinical Outcomes With Patient-Reported Outcomes
}

Graham Mulvaney, Steve Monk, Jonathan D. Clemente, Deborah Pfortmiller and Domagoj Coric

Int J Spine Surg 2020, 14 (s3) S31-S38

doi: https://doi.org/10.14444/7124

http://ijssurgery.com/content/14/s3/S31

This information is current as of April 26, 2023.

Email Alerts Receive free email-alerts when new articles cite this article. Sign up at: http://ijssurgery.com/alerts 


\title{
Expandable Interbody Spacers: A Two-Year Study Evaluating Radiologic and Clinical Outcomes With Patient- Reported Outcomes
}

\author{
GRAHAM MULVANEY, MD, ${ }^{1,2}$ STEVE MONK, MD,${ }^{1,2}$ JONATHAN D. CLEMENTE, MD,${ }^{4}$ DEBORAH \\ PFORTMILLER, PHD, ${ }^{1}$ DOMAGOJ CORIC, $\mathrm{MD}^{1,2,3}$ \\ ${ }^{1}$ Carolina Neurosurgery \& Spine Associates, Charlotte, North Carolina, ${ }^{2}$ Atrium Health Musculoskeletal Institute, Department of Neurological Surgery, \\ Charlotte, North Carolina, ${ }^{3}$ Atrium Health Musculoskeletal Institute, Spine Division, Charlotte, North Carolina,${ }^{4}$ Atrium Health's Carolinas Medical Center, \\ Department of Radiology, Charlotte, North Carolina
}

\begin{abstract}
Background: Posterior and transforaminal lumbar interbody fusion (PLIF and TLIF) have gained significant popularity for management of lumbar degenerative spine over the last 3 decades. Expandable interbody spacers are a newer technology that can increase in size after placement, theoretically minimizing the operative risks of static spacers without sacrificing radiographic correction. The goal of this study is to further evaluate the radiographic and clinical outcomes of expandable spacers.

Methods: This was a retrospective analysis of a prospective cohort that underwent elective 1- to 3-level PLIF/ TLIF with expandable interbody spacers from 2014 to 2020 at a single institution. Patient-reported outcome measures (PROMs) Oswestry Disability Index and Visual Analog Scale were collected at 6 weeks, 3 months, 6 months, and 12 months. Imaging was performed at 12 months, with follow up at 24 months in case of nonunion. Retrospective outcomes were computer tomography (CT) based and Bridwell-Lenke classification of fusion, radiographic parameters, and adverse events.

Results: A total of 50/53 (94.3\%) otherwise eligible patients had 12-month PROMs and CT imaging for analysis. Here, $50 \%$ were obese (body mass index $>30$ ), $58 \%$ had a smoking history, and $24 \%$ had a prior lumbar procedure. Also, 46/50 (92\%) patients fused by CT criteria. Significant decrease in PROMs was seen as early as 6 weeks postoperatively. The mean change in preoperative-to-postoperative global lordosis values was $3.8^{\circ} \pm 15.6^{\circ}$. There were $4(8 \%)$ intraoperative durotomies and $5(10 \%)$ patients requiring reoperation for nonunion.

Conclusions: Our study demonstrates the use of expandable spacers in a high comorbidity cohort with low complications, excellent improvement in PROMs despite minimal lordotic improvement, and high rates of fusion without recombinant human bone morphogenetic protein-2 (rhBMP-2) or iliac crest bone graft.

Level of Evidence: 4.

Clinical Relevance: Expandable interbody fusion can significantly improve outcomes for degenerative lumbar spondylosis, with good safety profile, and high fusion rates.

Special Issue

Keywords: interbody cages, fusion, radiographic parameters
\end{abstract}

\section{INTRODUCTION}

Various types of interbody fusion procedures have gained popularity in the treatment of degenerative lumbar spine pathologies over the past 3 decades. The posterior approaches, posterior or transforaminal interbody fusion (PLIF or TLIF), remain the workhorse techniques in addressing a range of spinal disease including lumbar stenosis with or without spondylolisthesis as well as spondylosis, kyphosis, and scoliosis. ${ }^{1}$ PLIF was initially described in the 1940s and 1950s, and the ensuing decades have seen a steady evolution in instrumentation, including interbody spacers, and surgical techniques as well as grafting options to refine the procedure by decreasing complication and improving clinical outcomes. PLIF was originally described as using iliac crest autograft as the structural graft in the interbody space, and static metallic cages were used in the initial description of TLIF. ${ }^{2-4}$ Subsequently, various static interbody spacers with differing biomaterials, eg, titanium, carbon fiber, poly-ethyl-ethyl ketone (PEEK), and geometries were developed. ${ }^{5}$ These interbody spacer designs 
had to work within the anatomic constraints of Kambin's triangle, ie, the exiting and traversing nerve roots as well as the lateral aspect of the thecal sac, and the geometric limitations of the disc space, ie, lordotic with anterior greater than posterior height.

PLIF techniques have traditionally been technically challenging with increased risk of complications of nerve root injury $(0.6 \%-24 \%)$ and incidental durotomy $(9 \%-19 \%)$ due to the traction on the dura necessary to gain access to the disc space. $^{6-10}$ TLIF and minimally invasive (MIS) TLIF, using a unilateral approach, were initially developed to decrease the complication rate associated with posterior interbody approaches. ${ }^{4}$ However, complications of the TLIF approach also include traction injury on the dorsal root ganglion with subsequent neuropathic pain or deficit as well as contralateral radiculopathy due to increased foraminal contralateral foraminal stenosis on the nondecompressed side. Fusion rates are reported to be somewhat lower for MIS TLIF compared to PLIF. $^{9-13}$ Other technique modifications, such as performing wide facetectomies, were also described to decrease the risk of dural traction injury. The introduction of pedicle screw fixation decreased the risk of graft dislodgement and subsidence. However, graft and spacer related complications related to PLIF and TLIF remain clinically impactful and may lead to poor patient outcome and/or technically challenging revision surgery. Interbody spacer modifications have also been developed to improve patient outcomes. Steerable and insert-and-rotate cages were introduced to increase the precision of spacer placement and lower the rate of spacer dislodgement. $^{14}$

Expandable spacers are the latest innovation designed to address these limitations of the posterior approach by delivering a relatively small spacer through a narrow anatomic corridor, theoretically decreasing the risks of nerve root injury and dural tear and, subsequently, expanding in the interbody space, maximizing disc space height. ${ }^{15}$ Despite the proliferation of expandable interbody spacers, there is relatively little evidence basis for the effectiveness of these devices in decreasing complications and facilitating fusion. While there has not been a welldesigned, prospective trial directly linking fusion to improved clinical outcomes, many studies have demonstrated a correlation between improvement in radiographic parameters and improvement in validated patient-reported outcome measures (PROMs) including the Oswestry Disability Index (ODI) and the Visual Analog Scale (VAS). ${ }^{16,17}$ The goal of the present study is to evaluate the clinical and radiographic outcomes of expandable interbody spacers in PLIF and TLIF.

\section{METHODS}

\section{Study Design and Data Collection}

\section{Design and Patient Population}

The current study retrospectively analyzed a prospective cohort of consecutive elective 1- to 3-level PLIFs and TLIFs performed by 2 surgeons at a single institution from 2014 to 2020. Local institutional review board approval was received for the retrospective analysis of patient medical records, PROMs, and preoperative and postoperative imaging. Inclusion criteria were 1- to 3-level elective PLIF or TLIF, minimum 12-month postoperative computed tomography (CT) scan to evaluate fusion, and baseline and 12-month PROMs. Exclusion criteria were use of a static interbody at any level, surgery performed for trauma, infection, or tumor, surgery performed on an emergent basis, and withdrawal from the study cohort or loss to follow up before 12-month imaging and PROMs collection (Table 1).

\section{Perioperative and Intraoperative Data}

Demographic data collected during the prospective cohort study included age, gender, and comorbidities such as smoking status, body mass index (BMI), diabetes, and prior lumbar surgical decompression or fusion. Comorbidities were listed and classified based on International Statistical Classification of Diseases and Related Health Problems, 10th Revision, criteria. Perioperative data collected included operative indication, surgical approach, surgical levels, operative time, estimated blood loss, and length of stay. Additionally, any intraoperative complications and severe adverse events (SAEs) were prospectively collected.

\section{Interbody Spacers}

Several different types of expandable spacers were used, the most common being StaXx XD Expandable Device and Velocity Expandable Interbody Device (Spine Wave, Inc., Shelton, CT) which use wafer technology to incrementally increase device height. After positioning the device in the interbody 
Table 1. Patient selection.

\begin{tabular}{l}
\hline Inclusion Criteria \\
\hline 1- to 3-level elective PLIF or TLIF \\
Expandable interbody cages \\
No exclusion for prior lumbar decompression or fusion \\
Minimum 12-mo postop PROMs \\
Minimum 12-month postop CT for fusion \\
Exclusion Criteria
\end{tabular}

Static interbody cage at any level

Surgery performed for trauma, infection, or tumor

Withdrawal from the initial study cohort

Loss to follow up before 12-mo imaging

Loss to follow up before 12-mo PROMs

Abbreviations: CT, computed tomography; PLIF, posterior lumbar interbody fusion; postop, postoperation; PROM, patient-reported outcome measure; TLIF, transforaminal lumbar interbody fusion.

space, a surgical gun is used to insert a selected number of wafers from a preloaded cartridge into the center of the implant, forming a mechanically stable column that results in increased height. The wafers, in 1-mm increments, are inserted individually until the desired height is achieved, providing in situ distraction. This technology allows controlled height expansion and may be used in both MIS and open interbody procedures. The StaXx XD device is composed of PEEK-OPTIMA. The Velocity device is composed of a PEEK-OPTIMA superior endplate and a titanium alloy inferior endplate which both incorporate a titanium plasma spray coating. The minimum unexpanded height is $7 \mathrm{~mm}$ for both systems, and the maximum expanded height is between 14 and $16 \mathrm{~mm}$. Information was retrospectively collected on brand, lordotic angle if present, insertion height, expansion height, volume of local autograft or morselized allograft, and location of placement (Table 2).

\section{Surgical Technique}

All operations were performed at a single institution by 2 surgeons. All operations were performed with mini-open technique. All unilateral interbody spacers were placed with a TLIF technique, and all bilateral placement were placed with a PLIF technique. After interbody spacer placement and expansion to the desired height, the remainder of the disc space filled with a combination of allograft and autograft. At this point, bilateral pedicle screw fixation was undertaken in the usual fashion with the remainder of the graft material placed posterolateral over the transverse processes.
Table 2. Interbody spacer types.

\begin{tabular}{lc}
\hline Spacer Brand & Spacer Levels, No. (\%) \\
\hline StaXx XD Expandable Device & $27(35.53)$ \\
ALTERA Spacer & $15(19.74)$ \\
RISE Spacer & $2(2.63)$ \\
CALIBER Spacer & $2(2.63)$ \\
FLXfit Interbody Fusion Device & $3(3.95)$ \\
Velocity Expandable Interbody Device & $18(23.68)$ \\
FlareHawk Expandable Interbody & $9(11.84)$ \\
Fusion System & \\
\hline
\end{tabular}

\section{Outcome Measures}

\section{Bony Fusion}

Adequate fusion was defined as the presence of bridging bone across the interbody spacer. An independent board-certified radiologist reviewed postoperative CT scans at 12 months and again at 24 months for patients that did not demonstrate bony fusion on the 12-month scan. The modified Bridwell-Lenke interbody fusion grading system was used to classify the degree of fusion on a 4point scale, with grades 1 and 2 representing fusion and grades 3 and 4 representing pseudoarthrosis. ${ }^{18,19}$

\section{Sagittal Balance}

Segmental and global lordosis were evaluated by an independent board-certified radiologist on preoperative and postoperative (12-month) radiographs or CT scans. Segmental lordosis was defined as the Cobb angle measured between the superior endplate of the rostral vertebral body and the inferior endplate (except at S1) of the caudal vertebral body at the fused level. Global lordosis was defined as the Cobb angle measured between the superior endplates of L1 and S1.

\section{Interbody Complications}

All patients were evaluated for graft subsidence and migration on the 12-month postoperative CT scan. Subsidence was defined as $>2 \mathrm{~mm}$ vertical erosion of the interbody through either the rostral or caudal endplate. Migration was defined as horizontal displacement of the interbody outside the anterior, posterior, or lateral limits of either the rostral or caudal endplate.

\section{PROMs}

Clinical outcomes were measured at baseline, 6 weeks, 3 months, 6 months, and 12 months using 2 validated PROMs, the ODI and the VAS. ${ }^{16,17}$ The ODI is a 10 -item questionnaire scored on a scale of 
Table 3. Demographic data.

\begin{tabular}{lc}
\hline Parameter & Value \\
\hline Age, y, mean \pm SD (range) & $61.62 \pm 9.1(42-79)$ \\
BMI, mean \pm SD (range) & $4.8(18.99-39.87)$ \\
Obese (BMI $>30)$, No. $(\%)$ & $25(50)$ \\
Sex, No. (\%) & $21(42)$ \\
Male & $29(56)$ \\
Female & \\
Smoking status, No. (\%) & $21(42)$ \\
Never & $25(50)$ \\
Former & $4(8)$ \\
Current & \\
Prior lumbar surgery, No. (\%) & $12(24)$ \\
Decompression only & $10(20)$ \\
Fusion & \\
Operative indications & $37(74.0)$ \\
Stenosis & $28(56.0)$ \\
Spondylosis with degenerative facet disease & $21(42.0)$ \\
Spondylolisthesis & $12(24.0)$ \\
Adjacent level disease & $11(22.0)$ \\
Failed back syndrome & $6(12.0)$ \\
Facet disease & $5(10.0)$ \\
Scoliosis & $5(10.0)$ \\
Synovial cyst & $2(4.0)$ \\
Radiculopathy & $2(4.0)$ \\
Herniated disc & $1(2.0)$ \\
Kyphosis &
\end{tabular}

Abbreviations: BMI, body mass index; SD, standard deviation.

$0-100 .{ }^{16,20}$ The VAS uses a pictorial system to characterize patient symptoms. ${ }^{17,20}$

\section{Statistical Methods}

All statistical analyses were performed using SPSS v27 (IBM Corp, Armonk, NY). Univariate nonparametric data are provided as frequency and percent, while parametric data are provided as mean \pm standard deviation. Bivariate analyses were conducted using paired $t$ tests, independent $t$ tests, and $\chi^{2}$ tests. General linear model repeated measures was used to examine group interaction in before and after PROMs. Statistical significance level was set at $P<.050$.

\section{RESULTS}

\section{Available Datapoints}

Sixty-eight patients were present within the database from the initial prospective cohort. Four patients were withdrawn from the study before receiving surgery, and 11 patients received static interbody placement at some level. This left 53 patients who met eligibility criteria for analysis in this retrospective study. Three patients were lost to follow up before 12-month clinic visit, generating a follow-up rate of $94.3 \%$ (50/53 patients). Near perfect PROMs scoring was collected, as 49/50 patients provided 6-week PROMs (ODI, VAS back, VAS right leg, and VAS left leg), and all 50/50 patients provided scores at 3, 6, and 12 months (total 796/800 datapoints), generating 99.5\% PROMs follow up and $100 \%$ follow up at 12 months. A total of 45 patients received evaluation of segmental and global lordosis, and 40 patients received Bridwell-Lenke individual level analysis of fusion, generating $95 \%$ patient follow up and $80 \%-$ $90 \%$ follow up for radiographic analysis at 12 or 24 months.

\section{Baseline Characteristics and Perioperative Data}

The mean patient age was $61.62 \pm 9.1$ years $(42-$ 79 years), with 21 males and 39 females. The mean BMI was $29.34 \pm 4.8$ (18.99-39.87), with 50\% patients meeting criteria for obesity (BMI > 30). Over half $(50 \%)$ of the cohort had a history of tobacco abuse or were current smokers $(8 \%)$. Nearly half $(44 \%)$ of the patients had a history of prior lumbar surgical intervention, with $11(22 \%)$ having had a previous lumbar fusion. The most frequent indications for surgery were stenosis (74\%), spondylosis with degenerative facet disease $(56 \%)$, spondylolisthesis $(42 \%)$, adjacent level disease $(24 \%)$, failed back syndrome $(22 \%)$, scoliosis $(10 \%)$, synovial cyst $(10 \%)$, radiculopathy $(4 \%)$, disc herniation $(4 \%)$, kyphosis $(2 \%$; Table 3$)$.

Twenty-seven $(54 \%)$ patients underwent singlelevel fusion, and $23(46 \%)$ underwent a 2- or 3-level fusion. A total of $13(26 \%)$ patients underwent TLIF, and $35(70 \%)$ patients underwent a PLIF, with 2 patients receiving a combination of both methods (4\%). On a per-level analysis, 22 (29\%) levels received TLIF (29\%), and 54 (71\%) levels received PLIF. The most frequently instrumented level was L4-L5 at 70\%, followed by L3-L4 and L5-S1, both at $16 \%$. The mean final expansion height was $11.05 \pm 2.1 \mathrm{~mm}(0-13 \mathrm{~mm})$, and the mean angle was $7.36^{\circ} \pm 3.4^{\circ}\left(0^{\circ}-15^{\circ}\right.$; Table 4$)$. The mean operative time was $186.52 \pm 49.1$ minutes (88-340 minutes). The mean estimated blood loss was $439.3 \pm 393.7 \mathrm{cc}(50-2450 \mathrm{cc})$; no patients required blood transfusion. Mean length of stay was $3.22 \pm 1.1$ days (2-7 days; Table 5).

\section{Radiographic Outcomes}

On analysis of CT-based criteria of fusion, 46/50 $(92 \%)$ of patients were deemed to have achieved fusion at 12 or 24 months. Bridwell-Lenke individual level grading of fusion was available for 40 
Table 4. Intraoperative data

\begin{tabular}{lc}
\hline & Value \\
\hline Single versus multilevel, No. (\%) & \\
1-level & $27(54)$ \\
2- or 3-level & $23(46)$ \\
Instrumented levels, No. (\%) & $1(2)$ \\
L1-L2 & $8(16)$ \\
L2-L3 & $16(32)$ \\
L3-L4 & $35(70)$ \\
L4-L5 & $16(32)$ \\
L5-S1 & \\
PLIF versus TLIF & \\
Patients, No. (\%) & $35(70)$ \\
PLIF & $13(26)$ \\
TLIF & $2(4)$ \\
PLIF and TLIF combo & \\
Levels, No. (\%) & $54(71)$ \\
$\quad$ PLIF & $22(29)$ \\
TLIF & \\
Expandable spacer dimensions, mean \pm SD (range) & $11.05 \pm 2.1(0-13)$ \\
Mean expansion height (mm) & $7.36 \pm 3.4(0-15)$ \\
Mean spacer angle ( $\left.{ }^{\circ}\right)$ & $8(16)$ \\
Allograft placement, No. $(\%)$ & $42(84)$ \\
Within & $10.17 \pm 3.9(4-20)$ \\
Within or around &
\end{tabular}

Abbreviations: PLIF, posterior lumbar interbody fusion; postop, postoperation; $\mathrm{SD}$, standard deviation; TLIF, transforaminal lumbar interbody fusion.

patients with 60 levels and demonstrated 44/60 $(73.3 \%)$ levels with complete fusion and 16 levels that did not achieve fusion at 24 months. The mean change in preoperative to postoperative segmental lordosis values was $3.8^{\circ} \pm 15.6^{\circ}$ (Table 6).

\section{PROMs}

Statistically and clinically significant improvement was noted across all PROMs at 12 months after surgery. The postoperative mean ODI was $25.96 \pm 19.9$ points $(0-74$ points, $P<.001)$ at 12 months (Figure 1). The mean postoperative VAS back pain was $25.46 \pm 27.8$ points $(0-93$ points, $P$ $<.001$ ) (Figure 2). The mean VAS right and left leg pain were $13.66 \pm 20.9$ points $(0-88$ points, $P<$ $.001)$ and $17.86 \pm 26.9$ points $(0-87$ points, $P<$ $.001)$ respectively (Figures 3 and 4).

Table 5. Perioperative data.

\begin{tabular}{lc}
\hline Parameter & Mean \pm SD (Range) \\
\hline LOS (d) & $3.22 \pm 1.1(2-7)$ \\
EBL (cc) & $439.30 \pm 393.7(50-2450)$ \\
Surgery time (min) & $186.52 \pm 49.1(88-340)$ \\
First follow up (d) & $35.80 \pm 9.0(15-62)$ \\
12-mo CT (d) & $359.42 \pm 42.2(95-433)$ \\
Last follow up (y) & $2.08 \pm 1.3(0-5)$ \\
\hline Abbreviations: CT, computed tomography; EBL, estimated blood loss; LOS, \\
length of stay.
\end{tabular}

Table 6. Radiographic outcomes.

\begin{tabular}{lcc}
\hline Parameter & \multicolumn{2}{c}{ Value } \\
\hline Bony fusion, No. $(\%)$ & Present & Absent \\
CT-based criteria $(\mathrm{n}=50)$ & $46(92)$ & $4(8)$ \\
Bridwell-Lenke scale $(\mathrm{n}=60$ levels), & $44(73.3)$ & $16(26.7)$ \\
$\quad$ complete fusion (B-L 1 or 2) & \\
Global lordosis $\left(^{\circ}\right)$, mean \pm SD (range) & $46.16 \pm 19.1(16-86)$ \\
Preoperative & $49.61 \pm 17.3(7-92)$ \\
Postoperative & $3.81 \pm 15.6(-38-28)$ \\
Post-pre difference & \\
\hline Abbreviations: CT, computed tomography; SD, standard deviation.
\end{tabular}

\section{Clinical Outcomes}

Patients who did not achieve fusion reported similar VAS back pain scores through 6 months, but at 12 months reported higher back pain score than patients that did achieve fusion $(\lambda=0.730, F=3.97$, $P=0.008)$. Patients that had a successful fusion were less likely to have to return to the operating room for any procedure $\left(\chi^{2}=7.12, P=.008\right)$. Patients that had a successful fusion were less likely to have a revision surgery $\left(\chi^{2}=20.41, P<.001\right)$. Patients that reported a SAE were less likely to have a successful fusion $\left(\chi^{2}=6.20, P=.013\right)$.

\section{Complications and Adverse Events}

Intraoperative complications primarily consisted of 4 patients $(8 \%)$ with intraoperative durotomy, with no reported nerve root traction injuries or postoperative neurologic deficits. Twelve (24\%) patients experienced a SAE postoperatively. Instrumentation failure and/or pseudoarthrosis was seen in $7(14 \%)$ patients, of which $5(10 \%)$ required revision surgery. Two $(4 \%)$ patients were readmit-

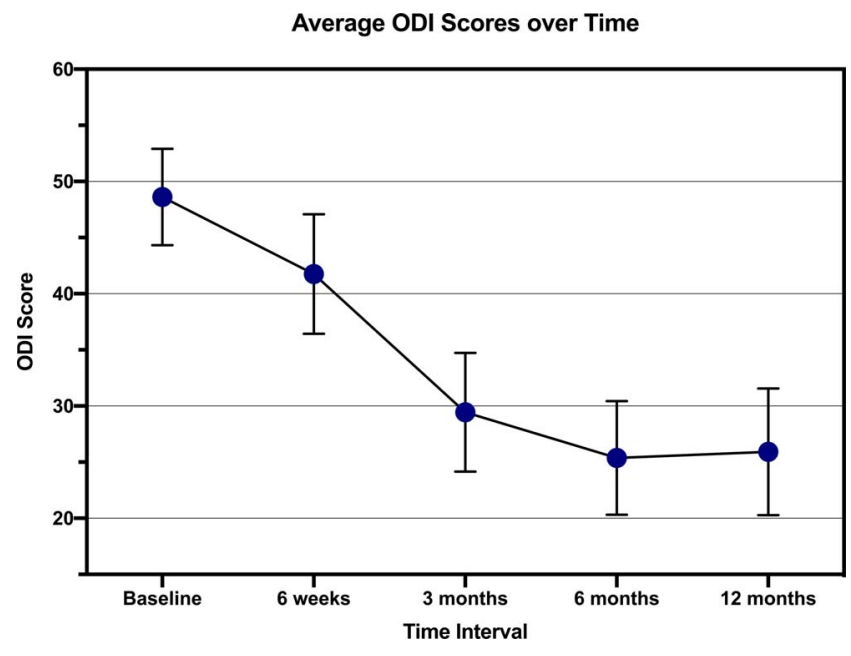

Figure 1. Average ODI scores over time error bars indicating $95 \%$ confidence interval. GLM repeated measures indicated the first significant improvement in odi score from baseline occurred at 3-months $(P<.001)$. 


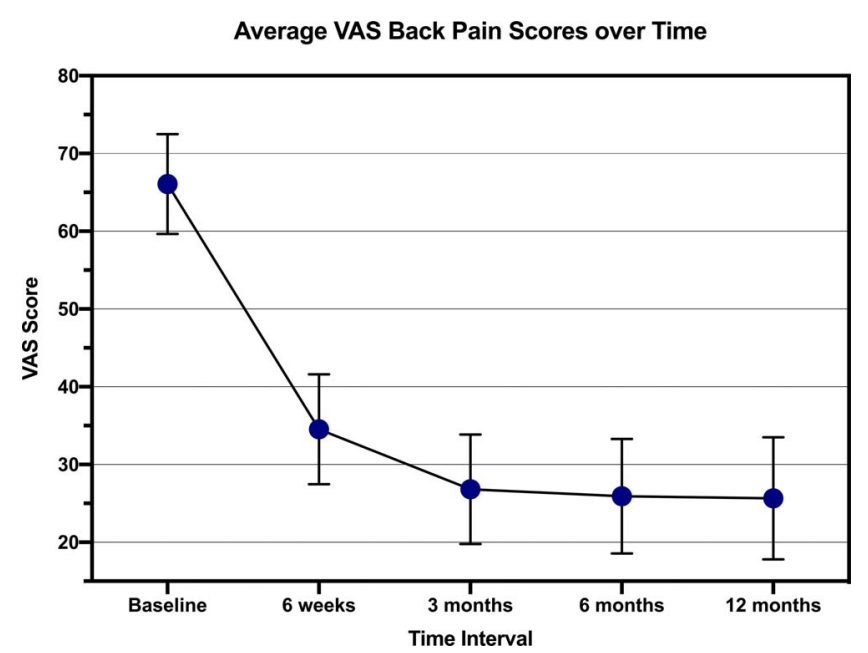

Figure 2. Average VAS back pain scores over time with error bars indicating $95 \%$ confidence interval. GLM repeated measures indicated the first significant improvement in back pain score from baseline occurred at 6-weeks $(P<.001)$.

ted for medical complications such as acute renal failure, coronary artery disease, and urinary tract infection. Two patients $(4 \%)$ required subsequent cervical spine surgery, and 1 patient had a prolonged postoperative hospitalization secondary to intraoperative durotomy. Subsidence was seen in $10(20 \%)$ of patients while migration was seen in 2 (4\%). Both complications were present in 1 patient. All patients with interbody subsidence and/or migration had incomplete or no fusion by Bridwell-Lenke scoring, but 4 of these patients were deemed to have fused by CT-based criteria.

Average VAS Left Leg Pain Scores over Time

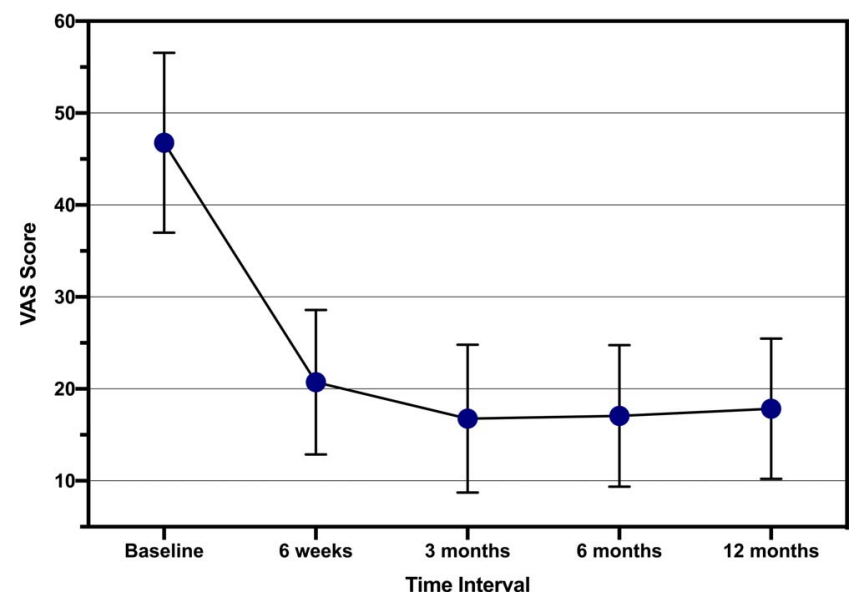

Figure 3. Average VAS left leg pain scores over time with error bars indicating $95 \%$ confidence interval. GLM repeated measures indicated the first significant improvement in left leg pain score from baseline occurred at 6-weeks $(P<$ $.001)$.

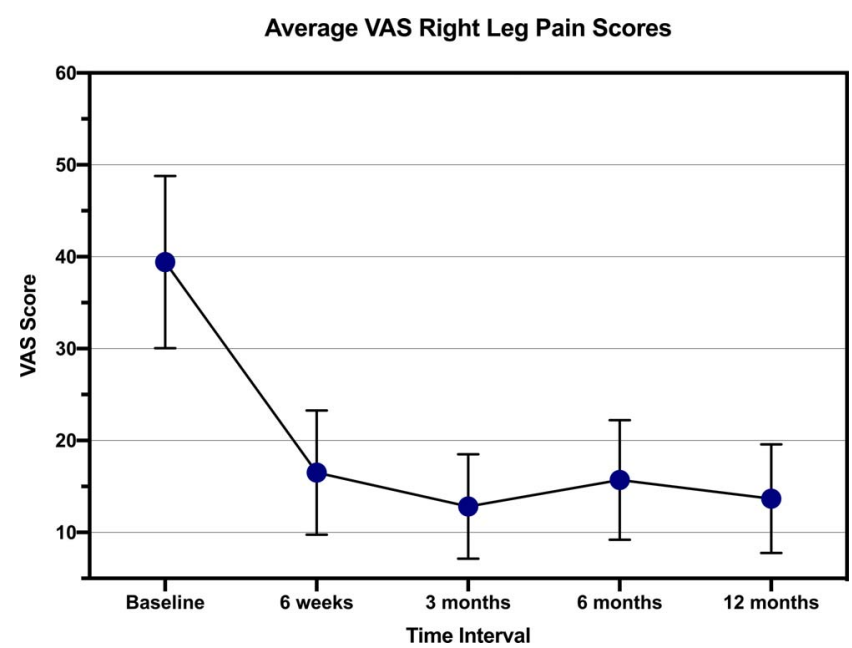

Figure 4. Average VAS right leg pain scores over time with error bars indicating $95 \%$ confidence interval. GLM repeated measures indicated the first significant improvement in right leg pain score from baseline occurred at 6weeks $(P<.001)$.

\section{DISCUSSION}

The rising popularity of lumbar interbody fusion over the past 2 decades has led to the concomitant evolution of a variety of interbody spacers. This proliferation of interbody spacers includes various combinations of different materials, architectures, and geometries with relatively little evidence basis for efficacy of any individual design. Initially, interbody spacers were designed at a fixed or static height. Expandable interbody spacers, whose height can be increased after insertion, allow for the smaller insertion height, theoretically minimizing some of the complications of PLIF or TLIF such as postoperative neurologic deficits. Additionally, by increasing disc space height, expandable spacers maximize the available interbody space for graft material. These theoretical benefits may be accentuated during MIS procedures due to the relatively limited decompression and disc space exposure. Potential concerns regarding expandable spacers include implant subsidence, mechanical failure, and limited graft chamber size which may negatively affect fusion rates.

There were no cases of subsidence or displacement in patients who went on to fusion in the present study, validating the concept that expandable spacers minimize endplate violation on insertion and provide good fill of the interbody space after expansion. Likewise, the present study reports high rates of fusion without the use rhBMP-2 or iliac crest bone graft, ameliorating concerns of limited space for interbody grafting. Furthermore, 
these fusion rates were achieved despite a majority of patients having a history of smoking. Although there is firm evidence for high fusion rates with the use of rhBMP-2, its use has also been associated with the risk of early osteolysis, which could negatively affect endplate integrity and increase the rate of spacer subsidence or displacement. ${ }^{21,22}$ Furthermore, we report significant improvements in PROMs despite including multilevel fusions in a relatively morbid patient population with a high rate of obesity $(50 \%)$ and previous lumbar procedures $(44 \%)$. Reoperation rates $(10 \%)$ were comparable to a prospective, randomized cohort treated with lumbar fusion for spondylolisthesis. ${ }^{23}$ There were no reoperations related to interbody spacer complications such as subsidence, displacement, migration, or mechanical failure.

There is a growing body of literature that suggests improvements in radiographic spinopelvic parameters, such as segmental and global lumbar (SL and GL) lordosis, correlate with improved patient outcomes. ${ }^{24-28}$ Traditionally, PLIF and TLIF approaches have demonstrated a limited ability to improve lordosis compared to anterior or lateral interbody fusion. ${ }^{29}$ The present study demonstrated only modest $\left(3.8^{\circ}\right)$ improvement in segmental lordosis but nonetheless reports statistically significant clinical and outcomes improvements in all PROMs. This cohort will continue to be followed to assess the potential impact of lordosis on adjacent level reoperation rates. For cases requiring more substantial correction of lordosis, surgical technique can be modified to include SmithPeterson osteotomy and spacer placement in the anterior portion of the disc space. ${ }^{30}$ This finding may have ramifications for MIS TLIF, where unilateral facetectomy limits the ability to restore lordosis. The results of the present study also reaffirm the importance of obtaining successful fusion in improving patient outcomes and avoiding reoperation.

The limitations of this study are that it is a retrospective review of prospectively collected data of a single institution study with only 2 surgeons involved. Additionally, there is no comparative control group. However, the patient population is relatively heterogenous, and multiple different types of expandable spacers were used, which is more reflective of a real-world surgical population and surgical experience.

\section{CONCLUSIONS}

The relative low complication rates, high fusion, and clinical success rates reported in the present study reaffirm the concept that expandable spacers facilitate open PLIF or TLIF. This study demonstrates improvements in radiologic parameters and PROMs over 1 to 2 years postoperatively in a realworld patient population with significant comorbidities. Given the rapid rate of spinal device development and adoption, it is critical that we continue to analyze these advancements to provide a firm evidence basis for safety and efficacy.

\section{REFERENCES}

1. Coric D, Branch CLJ. Posterior lumbar interbody fusion in the treatment of symptomatic spinal stenosis. Neurosurg Focus. 1997;3(2):e5. doi:10.3171/foc.1997.3.2.11

2. Cloward RB. The treatment of ruptured lumbar intervertebral discs by vertebral body fusion. I. Indications, operative technique, after care. J Neurosurg. 1953;10(2):154 168. doi:10.3171/jns.1953.10.2.0154

3. Briggs H, Milligan PR. Chip fusion of the low back following exploration of the spinal canal. J Bone Jt Surg. 1944;26(1):125-130.

4. Harms J, Rolinger H. [A one-stager procedure in operative treatment of spondylolistheses: dorsal tractionreposition and anterior fusion (author's transl)]. Z Orthop Ihre Grenzgeb. 1982;120(3):343-347. doi:10.1055/s-2008-1051624

5. Ray CD. Threaded titanium cages for lumbar interbody fusions. Spine (Phila Pa 1976). 1997;22(6):667-679; discussion 679-680. doi:10.1097/00007632-199703150-00019

6. Hosono N, Namekata M, Makino T, et al. Perioperative complications of primary posterior lumbar interbody fusion for nonisthmic spondylolisthesis: analysis of risk factors. $J$ Neurosurg Spine. 2008;9(5):403-407. doi:10.3171/SPI.2008.9.11.403

7. Elias WJ, Simmons NE, Kaptain GJ, Chadduck JB, Whitehill R. Complications of posterior lumbar interbody fusion when using a titanium threaded cage device. J Neurosurg. 2000;93(1 Suppl):45-52. doi:10.3171/spi.2000.93.1.0045

8. Davne SH, Myers DL. Complications of lumbar spinal fusion with transpedicular instrumentation. Spine (Phila $\mathrm{Pa}$ 1976). 1992;17(6 Suppl):S184-189. doi:10.1097/00007632199206001-00021

9. Okuda S, Miyauchi A, Oda T, Haku T, Yamamoto T, Iwasaki M. Surgical complications of posterior lumbar interbody fusion with total facetectomy in 251 patients. $J$ Neurosurg Spine. 2006;4(4):304-309. doi:10.3171/spi.2006.4.4. 304

10. Brantigan JW, Steffee AD, Lewis ML, Quinn LM, Persenaire JM. Lumbar interbody fusion using the Brantigan I/ F cage for posterior lumbar interbody fusion and the variable pedicle screw placement system: two-year results from a Food and Drug Administration investigational device exemption clinical trial. Spine (Phila Pa 1976). 2000;25(11):1437-1446. doi:10.1097/00007632-200006010-00017

11. Kim K-T, Lee S-H, Lee Y-H, Bae S-C, Suk K-S. Clinical outcomes of 3 fusion methods through the posterior approach 
in the lumbar spine. Spine (Phila Pa 1976). 2006;31(12):13511357; discussion 1358. doi:10.1097/01.brs.0000218635.14571.55

12. Peng CWB, Yue WM, Poh SY, Yeo W, Tan SB. Clinical and radiological outcomes of minimally invasive versus open transforaminal lumbar interbody fusion. Spine (Phila Pa 1976). 2009;34(13):1385-1389. doi:10.1097/BRS.0b013e3181a4e3be

13. Dhall SS, Wang MY, Mummaneni PV. Clinical and radiographic comparison of mini-open transforaminal lumbar interbody fusion with open transforaminal lumbar interbody fusion in 42 patients with long-term follow-up. J Neurosurg Spine. 2008;9(6):560-565. doi:10.3171/SPI.2008.9.08142

14. Sears W. Posterior lumbar interbody fusion for degenerative spondylolisthesis: restoration of sagittal balance using insert-and-rotate interbody spacers. Spine $J$. 2005;5(2):170-179. doi:10.1016/j.spinee.2004.05.257

15. Alimi M, Shin B, Macielak M, et al. Expandable polyaryl-ether-ether-ketone spacers for interbody distraction in the lumbar spine. Global Spine J. 2015;5(3):169-178. doi:10. 1055/s-0035-1552988

16. Fairbank JC, Couper J, Davies JB, O'Brien JP. The Oswestry low back pain disability questionnaire. Physiotherapy. 1980;66(8):271-273.

17. Von Korff M, Jensen MP, Karoly P. Assessing global pain severity by self-report in clinical and health services research. Spine (Phila Pa 1976). 2000;25(24):3140-3151. doi:10. 1097/00007632-200012150-00009

18. Bridwell KH, Lenke LG, McEnery KW, Baldus C, Blanke K. Anterior fresh frozen structural allografts in the thoracic and lumbar spine. Do they work if combined with posterior fusion and instrumentation in adult patients with kyphosis or anterior column defects? Spine (Phila Pa 1976). 1995;20(12):1410-1418. doi:10.1097/00007632-19950602000014

19. Chotivichit A, Fujita T, Wong T-H, Kostuik JP, Sieber AN. Role of femoral ring allograft in anterior interbody fusion of the spine. J Orthop Surg (Hong Kong). 2001;9(2):1-5. doi:10. $1177 / 230949900100900202$

20. Ostelo RWJG, Deyo RA, Stratford P, et al. Interpreting change scores for pain and functional status in low back pain: towards international consensus regarding minimal important change. Spine (Phila Pa 1976). 2008;33(1):90-94. doi:10.1097/ BRS.0b013e31815e3a10

21. McClellan JW, Mulconrey DS, Forbes RJ, Fullmer N. Vertebral bone resorption after transforaminal lumbar interbody fusion with bone morphogenetic protein (rhBMP-2). $J$ Spinal Disord Tech. 2006;19(7):483-486. doi:10.1097/01.bsd. $0000211231.83716 .4 \mathrm{~b}$

22. Lewandrowski K-U, Nanson C, Calderon R. Vertebral osteolysis after posterior interbody lumbar fusion with recombinant human bone morphogenetic protein 2: a report of five cases. Spine J. 2007;7(5):609-614. doi:10.1016/j.spinee.2007.01. 011

23. Ghogawala Z, Dziura J, Butler WE, et al. Laminectomy plus fusion versus laminectomy alone for lumbar spondylolisthesis. $N$ Engl J Med. 2016;374(15):1424-1434. doi:10.1056/ NEJMoa 1508788

24. Glassman SD, Bridwell K, Dimar JR, Horton W, Berven S, Schwab F. The impact of positive sagittal balance in adult spinal deformity. Spine (Phila Pa 1976). 2005;30(18):2024 2029. doi:10.1097/01.brs.0000179086.30449.96

25. Le Huec JC, Charosky S, Barrey C, Rigal J, Aunoble S. Sagittal imbalance cascade for simple degenerative spine and consequences: algorithm of decision for appropriate treatment. Eur Spine J. 2011;20(Suppl 5):699-703. doi:10.1007/s00586-0111938-8

26. Tempel ZJ, Gandhoke GS, Bolinger BD, et al. The influence of pelvic incidence and lumbar lordosis mismatch on development of symptomatic adjacent level disease following single-level transforaminal lumbar interbody fusion. Neurosurgery. 2017;80(6):880-886. doi:10.1093/neuros/nyw073

27. Rothenfluh DA, Mueller DA, Rothenfluh E, Min K. Pelvic incidence-lumbar lordosis mismatch predisposes to adjacent segment disease after lumbar spinal fusion. Eur Spine J. 2015;24(6):1251-1258. doi:10.1007/s00586-014-3454-0

28. Matsumoto T, Okuda S, Maeno T, et al. Spinopelvic sagittal imbalance as a risk factor for adjacent-segment disease after single-segment posterior lumbar interbody fusion. $J$ Neurosurg Spine. 2017;26(4):435-440. doi:10.3171/2016.9. SPINE16232

29. Hsieh PC, Koski TR, O’Shaughnessy BA, et al. Anterior lumbar interbody fusion in comparison with transforaminal lumbar interbody fusion: implications for the restoration of foraminal height, local disc angle, lumbar lordosis, and sagittal balance. J Neurosurg Spine. 2007;7(4):379-386. doi:10.3171/ SPI-07/10/379

30. Jagannathan J, Sansur CA, Oskouian RJJ, Fu K-M, Shaffrey CI. Radiographic restoration of lumbar alignment after transforaminal lumbar interbody fusion. Neurosurgery. 2009;64(5):955-963; discussion 963-964. doi:10.1227/01.NEU. 0000343544.77456 .46

Disclosures and COl: Approval was obtained from our local institutional review board. Dr. Coric receives royalties from Spine Wave, Globus Medical, Medtronic, Integrity Implants, and Stryker, is a consultant for Spine Wave, Globus Medical, Medtronic, and Integrity Implants, and owns stock in Spine Wave. For the remaining authors, none are declared.

Corresponding Author: Domagoj Coric, MD, Carolina Neurosurgery \& Spine Associates, 225 Baldwin Ave, Charlotte, NC 28204. Phone: (704) 376-1605; Email: Domagoj.Coric@CNSA. com.

Published 9 December 2020

This manuscript is generously published free of charge by ISASS, the International Society for the Advancement of Spine Surgery. Copyright (c) 2020 ISASS. To see more or order reprints or permissions, see http://ijssurgery.com. 